\title{
(2) OPEN ACCESS \\ Will you give my kidney back? Organ restitution in living-related kidney transplantation: ethical analyses
}

\author{
Eisuke Nakazawa, ${ }^{1}$ Keiichiro Yamamoto, ${ }^{1}$ Aru Akabayashi, ${ }^{1}$ Margie H Shaw ${ }^{2}$ \\ Richard A Demme, ${ }^{2}$ Akira Akabayashi ${ }^{1,3}$
}

'Department of Biomedical Ethics, Faculty of Medicine, The University of Tokyo, Bunkyo, Japan

${ }^{2}$ Division of Medical Humanities and Bioethics, University of Rochester Medical Center, Rochester, New York, USA ${ }^{3}$ Division of Medical Ethics, New York University School of Medicine, New York, New York, USA

\section{Correspondence to} Dr Eisuke Nakazawa, Department of Biomedical Ethics, Faculty of Medicine, The University of Tokyo Graduate School of Medicine, Bunkyo, Tokyo 113-0033, Japan; nakazawaeisuke-tky@umin. ac.jp

Received 9 April 2019 Revised 4 September 2019 Accepted 8 September 2019

Published Online First

19 September 2019
Check for updates

(c) Author(s) (or their employer(s)) 2020. Re-use permitted under CC BY-NC. No commercial re-use. See rights and permissions. Published by BMJ.

To cite: Nakazawa $\mathrm{E}$ Yamamoto K, Akabayashi A, et al. J Med Ethics 2020;46:144-150.

\section{ABSTRACT}

In this article, we perform a thought experiment about living donor kidney transplantation. If a living kidney donor becomes in need of renal replacement treatment due to dysfunction of the remaining kidney after donation, can the donor ask the recipient to give back the kidney that had been donated? We call this problem organ restitution and discussed it from the ethical viewpoint. Living organ transplantation is a kind of 'designated donation' and subsequently has a contract-like character. First, assuming a case in which original donor $(A)$ wishes the return of the organ which had been transplanted into $B$, and the original recipient (B) agrees, organ restitution will be permissible based on contract-like agreement. However, careful and detailed consideration is necessary to determine whether this leaves no room to question the authenticity of B's consent. Second, if $B$ offers to give back the organ to $A$, then B's act is a supererogatory act, and is praiseworthy and meritorious. Such an offer is a matter of virtue, not obligation. Third, if A wishes B to return the organ, but $B$ does not wish/allow this to happen, it is likely difficult to justify returning the organ to $A$ by violating $B$ 's right to bodily integrity. But B's refusal to return the donated organ cannot be deemed praiseworthy, because $B$ forgets the great kindness once received from $A$. Rather than calling this an obligation, we encourage $B$ to consider such virtuous conduct.

\section{INTRODUCTION}

Since the successful completion of the first kidney transplantation from one identical twin to another in $1954,{ }^{1}$ living kidney donors have supported a large number of transplantations. For example, in 2016, there were approximately 89823 kidney transplants performed worldwide, with approximately 40.2\%, just over 36000 , supported by living donor kidney transplants. ${ }^{2}$ Wainright et al found that between 1 April 1994 and 30 September 2016 a total of 123526 living kidneys were donated in the USA. Of those living kidney donors, 218 went on to develop kidney failure/end-stage renal disease (ESRD). ${ }^{3}$ As evident from these reports, there are, in fact, cases in which the donor's life itself is put in danger, when their remaining kidney stops functioning properly after undergoing living kidney donation. In this paper, we consider a scenario where a living kidney donor becomes in need of renal replacement treatment due to dysfunction of the remaining kidney after donation. Can the donor ask the recipient to give back the kidney that had been donated, in order to avoid becoming dependent on dialysis, instead of asking a relative for a kidney, or being put on a waiting list for kidney transplantation from deceased donors? We will perform a thought experiment in order to further understand the ethics of living donor kidney transplantation.

\section{CASE}

$\mathrm{Mr}$ A offered to be a living-related kidney donor for his relative, $\mathrm{Mr} \mathrm{B}$, who developed renal failure. His postoperative course was smooth, and a year went by without any problems. One day, A, the donor, was involved in a motor vehicle accident, and he lost his remaining kidney function due to acute kidney injury from which he did not recover. None of his relatives could provide a kidney to A, and the waiting list for kidney transplantation from deceased donors suggested a long waiting time. A felt strongly against being on renal dialysis, which would restrict his life three times a week. Can A demand $\mathrm{B}$ to give back his kidney?

\section{DISCUSSION}

\section{Medical aspects}

From a medical perspective, the act of returning an organ that has once been donated (hereafter, organ restitution) is not permissible if serious safety issues arise due to returning the organ. Accumulating cases have reported on the reuse of transplanted kidneys. ${ }^{4-11}$ The anecdotal success of this procedure does not suggest it could routinely be accomplished safely.

Medically, the greatest risk of organ restitution is potential damage to the removed kidney when retransplanted into A from B. The surgery is expected to be difficult due to tissue adhesion that developed after transplantation.

Another risk is deterioration of the transplanted kidney, which could be caused by side effects from immunosuppressive agents (calcineurin inhibitors used in almost all cases are nephrotoxic), chronic rejection, post-transplant artery vasculopathy or viral infection. Moreover, while the risk of rejection is low for A, as his own kidney is retransplanted, there remains a slight risk of rejection due to the microchimerism of some immunogenic cells from the first transplant recipient.

Additionally, out of respect for the principle of non-maleficence, physicians would refrain or resist from taking the kidney out of the recipient even with his consent as returning a patient to dialysis may decrease his expected remaining life years and quality of life (QOL) compared with continuing on with a functioning kidney transplant. This is an example of conscientious refusal of treatment by the 
Table 1 Matrix of attitudes towards organ restitution

\begin{tabular}{llll}
\hline & & A & \\
\cline { 3 - 4 } & & Yes & No \\
\hline B & Yes & I & II \\
& No & III & IV \\
\hline
\end{tabular}

physician. Even if B agrees, it is certainly possible that a physician may refuse to perform medical acts that will have a serious negative impact on B's health, due to reasons of conscience. In this case, the negative effects on B's health include the risks associated with kidney extraction and return to dialysis. In general, prognosis is worse with dialysis compared with kidney transplantation. The danger of complications also increases. Moreover, QOL likely will decrease as well, given the symptoms, time and medical costs associated with dialysis. Therefore, the physician might conscientiously refuse to perform treatments on B that will have such negative effects. This, however, requires additional consideration. Usually, live kidney transplantations are also surgeries that have a risk of negative effects on the donor, such as exacerbation of hypertension. Having only one kidney may have a negative impact on the health of donor A. While there may be positive psychological and social effects on the donor in both cases, the difference between removing one kidney from a donor who has another and removing the only kidney is substantial. Therefore, while it is possible that a physician may conscientiously refuse to take part in organ restitution, conscientious refusal is not specific to organ restitution.

\section{Ethical and legal analysis}

Agenda for ethical debate: axes of ethical evaluation and two types of contracts

First, to set an agenda for ethical debate, we will sort out possible attitudes that may be assumed by key persons A and B. A's attitudes towards organ restitution can be classified into a 'Yes' condition (for wishing and/or permitting the return of the organ which had been transplanted to B) and the opposite 'No' condition. Similarly, B's attitudes can be classified into positive 'Yes' and negative 'No' conditions (table 1).

The ethical question that we will repeat throughout this paper is whether or not organ restitution is ethically permissible under each condition (I-IV). In the following sections, we extract ethical issues in the context of each of these four conditions.

Second, we introduce contract concepts to our discussion about living organ transplantations. In general, living donor organ transplantation can be regarded as a sort of contract that commits the donor to donate their organ to the recipient. As such, a donor-recipient pair is formed, which is characteristic of normal living donor organ transplantation; this is not the case in organ transplantation from deceased donors. In the above sense, living donor organ transplantation is always based on directed donation. So, we now delineate the two contract concepts at work in the relationship between donor and recipient when it comes to living kidney transplantation in order to clarify our discussion. One is the donation (gift) contract, and the other is the organ restitution contract. In the donation contract, the kidney is given from donor A to recipient $B$ as a gift. Because the gifted kidney is transferred from donor $\mathrm{A}$ to recipient $\mathrm{B}$, donor A can make no legal claim against recipient $B$ to return the organ provided. Therefore, recipient B has no legal obligation towards A for the possession of the organ provided as a gift (that said, as we argue below, the possibility that some other norm or morality exists between the two of them, other than a legal obligation, cannot be denied). The donation (gift) contract relies, in part, on the 'Theory of Property' as represented by John Locke's concept of property. ${ }^{12}$ For instance, according to Robert Nozick who, while partially criticising Locke's ownership theory, defended the notion of property rights as self-ownership: 'The central core of the notion of a property rights in $\mathrm{X} \ldots$ is the right to determine what shall be done with $\mathrm{X}$, the right to choose which of the constrained set of options concerning $X$ shall be realized or attempted. ${ }^{13}$ Based on the premise of such rights combined with the principle of autonomy and respect for the individual's right of self-determination, including around issues of bodily integrity, retransplantation (into A) is ethically permissible. 'Permissibility' in this sense is grounded in B's right to self-ownership of the organ as well as his right to disclaim it, or his right to donate the organ. ${ }^{14}$

There have been various critiques of Robert Nozick's libertarian principle of self-ownership. One of the most prominent holds that permitting libertarianism with respect to organs would make possible a market in human organs. Opinions are divided on the marketing of organs, but we are opposed to it (for more on these debates, see refs 15-18). Furthermore, some argue against Nozick's thesis of libertarian self-ownership itself, and others point out differences between the thesis and Locke's own doctrine of self-ownership. ${ }^{19}{ }^{20}$ For the sake of argument, however, in order to emphasise the contrast between donation contracts and loan for use contracts, this article assumes a Nozick-style principle of strong self-ownership.

The organ restitution contract, on the other hand, is a loan for use contract. Under such a restitution contract, B (recipient) is obligated to provide the transplanted organ to A (donor), if such a need arises. This form of contract resembles the precarium in Roman law; recipient $\mathrm{B}$ is thought to have the right to use the kidney as long as donor A permits it. Therefore, the organ restitution contract differs from a gift, since donor A can legally demand that recipient $B$ return the provided organ, and recipient $\mathrm{B}$ bears the legal obligation (more specifically, full responsibility) to return it when donor A demands.

The concept of contract we are using is the legal concept. In this case, a contract refers to the legal act that establishes an agreement of intent between two or more involved parties. More specifically, the organ restitution contract that we envision is similar to a 'loan for use' contract. The basis in legal philosophy for this organ restitution contract is the basic idea of the freedom of contract. The freedom of contract could be said to originate in Lockean contract theory. The principle is that entering into a contract is an individual right, and thus if a contract is the result of the free choice of two or more parties, public authorities must not intervene. Also in Japan's Civil Code, there is presumed to exist the freedom to form a contract (or to choose not to), the freedom to select one's partner in a contract, the freedom to decide on the content of the contract and the freedom to select the form of the contract. ${ }^{21}$

In Japan's specific laws, however, limitations are at times imposed on free contracts. In the case of organ restitution contracts, the relevant law would be the law governing organ transplantation. A prohibition on buying and selling organs was added to Japan's Organ Transplantation Act when it was revised in 2009 .

\section{Article 11}

1 No one may receive an economic benefit in exchange for providing or having provided organs to be used in transplantation, or request or promise to do so. 
2 No one may provide an economic benefit in exchange for receiving or having received organs to be used in transplantation, or apply or promise to do so.

3 No one may receive an economic benefit in exchange for acting or having acted as an intermediary arranging the provision or receiving of organs to be used in transplantation, or request or promise to do so.

4 No one may provide an economic benefit in exchange for receiving or having received intermediary services arranging the provision or receiving of organs to be used in transplantation, or apply or promise to do so.

5 For organs involved in acts that violate any of the above items, no one may knowingly extract or use such organs in transplantation procedures.

6 Exchange of payment prohibited in items 1 through 4 does not include the costs required for transportation, communication, or the extraction, preservation, or transfer of organs to be used in transplantations, or those costs usually recognised as necessary in providing or receiving organs to be used in transplantation, or serving as an intermediary. ${ }^{22}$

While this statute prohibits providing or promising organs for the purpose of economic benefit, it cannot, in our view, restrict organ restitution contracts. On the other hand, on the level of general rather than specific laws, one may assume it would be possible to pursue a civil lawsuit. Article 90 of Japan's Civil Code includes the statement 'any legal act that violates public order or standards of decency is deemed invalid.' If organ restitution contracts violate public order and standards of decency, such contracts would be illegal. Yet, acts thought to violate the rules of public order and standards of decency are those lacking fairness, such as non-consensual marriage contracts and click fraud. It is unclear whether an organ restitution contract would be regarded as an act that violates public order and standards of decency.

\section{Condition I: does the consent of both parties justify the act of returning the donated organ?}

Let us assume a case in which A wishes the return of the organ which had been transplanted to B, and B agrees. Their intentions are compatible, since $\mathrm{B}$ is also positive about returning the organ. What is subject to ethical consideration, however, is the process by which their intentions are formed.

First, we examine the case based on the viewpoint of the donation (gift) contract. The authenticity of B's self-determination warrants examination. If B's self-determination is authentic, then retransplantation of his (donated) organ can be ethically justified. However, we need to carefully consider whether B's self-determination is authentic. As previously pointed out, ${ }^{23}$ recipients of kidney transplants from living donors possibly may develop a feeling of redemption, and they might choose the option of returning the donated organ out of a guilty conscience. Under such circumstances, they are psychologically influenced to make the decisions, and their self-determination regarding the consent, for this reason, is not without pressure.

Second, we examine the case that includes an understanding between $\mathrm{A}$ and $\mathrm{B}$ regarding organ restitution. If it were lawful to have an organ donation contract that includes such a clause specifying the return of the organ (ie, it does not go against public policy), then it is obligatory for B to return the organ to $\mathrm{A}$ in accordance with the contract. Absent a strong public policy justification, in cases where A and B have a voluntary agreement based on freedom of contract, under no influence other than their own intentions, having a third party tear up the contract and prevent $\mathrm{B}$ from returning the organ would lack ethical legitimacy.

However, the same point can be raised about the legitimacy of the contract that obligates B to return the transplanted organ. Consider the following case: B, prioritising the short-term profit (of receiving an organ), brings up a contract that specifies his obligation to return the organ to A, saying, 'Please donate your kidney to me now, and I promise I will give it back to you if you ever need it again.' Or, in another case, A might bring up the contract saying, 'I will donate my kidney to you (B), if you agree to give it back to me if I (A) need it.' If B responds to this offer, it is possible that he might not have contemplated the contract enough, overestimating his short-term gain and underestimating the likelihood of the reality that necessitates him to return the organ to A. Moreover, this contract puts B in a vulnerable position as a recipient of the original kidney transplantation (from $\mathrm{A}$ to $\mathrm{B}$ ). There is a possibility that B reluctantly agrees, even though he finds the contract offensive. Made under these implicit pressures, the contract cannot be regarded as authentic. 'Authentic contract' indicates a contract free from defect or based on consent in the mutual respect for personhood between A and B. In other words, here the contract and consent are autonomous, and the condition is that it is voluntary, which means there is no coercive intervention by either party or a third party, and no exploitation.

Third, we consider the ethical issues surrounding A's request that B return the organ in terms of 'asking a favor'. This is a discussion from the standpoint of virtue. The phrase 'asking a favor' is used here to connote something weaker than an order or demand. Instead, it is used to express a wish. A's desire for organ restitution from B might be considered 'asking a favor,' but it could not be called an upstanding act in certain contexts. For example, it may be that A is condescendingly expecting B's gratitude. Generally, living organ transplantation is based on the donor's altruistic act. In this case, B has stopped dialysis and enjoys a higher QOL due to A's altruism. So let us say that as time passes, A comes to require a kidney, and asks B to show the virtue of altruism. If $B$ happens to refuse this, A condemns B's selfishness and lack of reciprocity. In that case, A is selfish in a reflexive way. Even if A sees merit in altruistic behaviour, and holds the belief that this is simply asking similarly altruistic behaviour of $\mathrm{B}$, in this context the request for organ restitution from A, who stands to benefit, cannot be called praiseworthy from an ethical perspective. The situation would differ in another context. For example, this could be a case in which A is fully aware that organ restitution would lower B's QOL, yet still asks the favour of organ restitution by clinging to B's goodwill. Generally, if a patient with a failing kidney asks relatives to consider donating a kidney, this request is not something to be condemned. Similarly, if A is fully aware of the burden on B, including the risks of organ restitution surgery and the decline in QOL, and appeals to B's goodwill, which is to say appeals to $\mathrm{B}$ without obligating $\mathrm{B}$ to return the organ, then this normally would not be blameworthy, ethically speaking. That A can ask this favour of B may be evidence that relations between them are good.

\section{Condition II: offer to give back the organ}

In condition II, B offers to give back the organ, raising the following ethical issues.

First, it is not obligatory for B to return the donated organ. As Thomson has shown in her famous violinist's case concerning the issue of abortion, forcing someone to exercise altruism that has an element of self-sacrifice as a matter of legal rights, or 
demanding it as a deed of the good Samaritan, both involve potential ethical problems. ${ }^{24}$ To elaborate further using different terms (which Thomson did not use), one cannot request such altruism as 'perfect obligation' or 'imperfect obligation'. According to a common definition, perfect obligation implies a legal duty, and a breach of this duty is a matter of legal liability. On the other hand, imperfect obligation does not entail a legal duty; however, as Schumaker stated, imperfect obligation is an obligation, so not fulfilling it is a violation of a certain moral request. ${ }^{25}$ In other words, both perfect obligation and imperfect obligation are enforceable moral requests, although to a varying extent. Actions that conform to these moral requests are ethically evaluated as 'just,' and those that do not as 'unjust'. Under this approach, it cannot be considered unjust (or ethically evaluated as such) even if B does not offer to return the organ. In other words, a difficulty arises in classifying B's offer (to give back the organ) as an imperfect obligation.

Second, rather, it is an act that reflects the virtuous character of $\mathrm{B}$, or the demonstration of B's virtue. In this sense, B's virtue may be interpreted as 'benevolence' or 'conscientiousness'. ${ }^{26} \mathrm{~B}$ is aware of the fact that B has been kept alive by A, and is always grateful and feels indebted. Thus, B would do anything for A, if A was put in a difficult situation. B should be admired as a virtuous person, for behaving so altruistically. We consider B's offer to return the organ based on aretaic - rather than deonticethics, and evaluate the offer mainly at the level of 'good or bad personality'. ${ }^{27}$ According to this idea, the act of B to give back the kidney to A (as a display of altruism) can be classified as supererogation, that is, an act beyond the domain of 'obligation' that accompanies ethical evaluation of 'just/unjust'. ${ }^{28} 29$ The following definition of 'supererogatory acts' is typically adopted: 'An act can be classified into the supererogatory "if and only if it meets the following three conditions: (1) it's morally optional, (2) it's morally praiseworthy, and (3) it goes beyond the call of duty". ${ }^{30}$ With this notion of supererogation in mind, the act of A to donate his organ to B in the first place could be understood as a supererogatory act, since it is a selfless, altruistic act of gift giving. Similarly, B's offer to give back the organ to A is also a supererogatory act, and is praiseworthy and meritorious. Such an offer is a matter of virtue, not obligation.

In condition II, A is also altruistic. Although B offers to return the organ, A's refusal of this benefits B. Of course, there could be various reasons for A's refusal. For example, because the organ restitution surgery would place a burden on B, A might feel remorseful about this risk borne by $\mathrm{B}$, and refuse the return of the organ. This is the manifestation of A's altruism, and for this A would be judged to be a person of virtue. There are, however, other conceivable reasons for refusal not based in altruistic virtue. It could be that $\mathrm{A}$ is opposed to creating any sort of debt with $\mathrm{B}$, or that $\mathrm{A}$ has turned his back on life and given in to despair, or that he has (in the Kantian sense) goodwill and obligation of the kind that cannot be reduced to any kind of benefit.

However, the virtue of altruism is potentially culture dependent. In some cultural and religious context, 'neighborly love' and 'benevolence' define the moral principles of organ donation. A gift based on neighbourly love is to be given freely without expectation of a return. Meanwhile, B's offer to give back the organ, which may or may not be based on neighbourly love or benevolence, could reflect other cultural values. For instance, in some cultures, one would always reciprocate gift giving. Receiving a gift is like owning a debt to the giver, so the consequence of failing to repay the 'debt' may be to face the sanction of being labelled by society as a 'shameless person' or a 'person devoid of common sense'. With such a 'shame' culture in the background, B's offer to give back the organ may be viewed as an expression of virtue described as moderation, civility or loyalty. ${ }^{26}$ Moreover, the demonstration of virtue in this sense is not necessarily supererogatory. Because, if it is, B should not face sanction or be ethically judged as 'unjust' due to his act (ie, not offer to give back the organ). ${ }^{28}$ It is important to note that, depending on the context, demonstration of virtue may be classified either as supererogation or imperfect obligation. Accordingly, depending on the culture or context, B not offering to give back the organ might rather be considered a failure to fulfill an imperfect obligation, and in some cases ethically evaluated as 'unjust'.

Based on the above discussions, B's offer to give back the organ could be evaluated from the perspective of virtue as well, either as an imperfect obligation or supererogatory act (virtuous act), depending on the context.

\section{Condition III: refusal to give back the organ}

In condition III, A wishes B to return the organ, but B does not wish/allow this to happen. Considering organ transplantation in light of ownership rights, the following two ethical issues can be raised.

First, if the original organ transplantation from A to B is treated as a transfer or gift of the ownership of the organ from A to $\mathrm{B}$, then naturally, the possession of the organ donated from $\mathrm{A}$ can then be claimed by B. In condition III (ie, B does not agree to give back the organ), it is likely difficult to justify returning the organ to A by violating B's right to ownership.

Second, if the original organ transplantation (from A to B) was conducted on the basis of some contractual agreement that included an understanding about specifying organ restitution, resolution is more complex? In this scenario, we assume that the contract is an authentic one. Based on this contract, B's refusal to fulfil the contract (condition III) is no different from B wishing to withdraw the consent in the organ restitution contract. For $\mathrm{B}$ to withdraw his consent means breaking the promise (that he would give back the donated organ to A) he had made before undergoing organ transplantation. But is it acceptable to withdraw consent? If it is, it makes no sense for A to approach B with the contract in the first place, since no practical action would be derived from it. Conversely, if $\mathrm{B}$ is to propose the contract to A, there is no point to the contract if it allows B's consent withdrawal, which is the same as not making the promise to give back the organ in the future. How about when consent withdrawal is not permitted, or if the contract simultaneously includes the agreement that consent withdrawal would not be possible? At that point, can $\mathrm{A}$ have the organ returned in accordance with the contract, despite the fact that $\mathrm{B}$ currently has a negative intention to have the organ removed? This issue will be discussed in the Judgement section.

In addition to the two aforementioned issues, here we bring up the third issue regarding B's refusal to return the donated organ. In Condition II: Offer to Give Back the Organ section, we discussed that B's offer to return the donated organ is either an imperfect obligation or supererogatory act; in either case, B deserves respect as a praiseworthy individual. Correspondingly, under condition III, B's refusal to return the donated organ cannot be considered praiseworthy. That is, B's attitude to reject the request of A can be viewed as his forgetting the great kindness once received from A. Although this cannot be regarded as a breach of duty, some cultures would not allow being ungrateful in this way. In that case, B would be sanctioned in some form by the community, even if not legally. 


\section{Condition IV: a case in which the donated organ could never be returned}

In a case where both $\mathrm{A}$ and $\mathrm{B}$ have negative attitudes towards organ restitution, the intentions of both parties are in agreement and no conflicts arise.

\section{JUDGEMENT}

Now that we have consolidated the ethical issues related to organ restitution in the context of each of the four conditions (IIV), we examine whether organ restitution is permissible in each scenario. To state the conclusion first, we assert that B should give back the donated organ under conditions I and III, in which A wishes the organ previously transplanted to B be returned. On the other hand, under conditions II and IV (ie, A does not wish the organ to be returned), we think there is no need for this act to take place.

It is important to note that the paper focuses on, and the conclusion concerns the donor and the recipient. Living organ donation is one of the most ethically challenging issues in medicine, and requires physician participation. If one of our major precepts is 'do no harm', physicians and surgeons are only allowed to proceed with living organ transplant if there is minimal risk or harm, and great benefit. The ethics of transplantation considers the risk/benefit analysis for both the donor and the recipient. If the considered kidney removal would be known to result in kidney failure of the donor, physicians could not ethically participate in this action. That risk to the donor would outweigh any benefits to the donor.

Let us elaborate. In condition I, both $\mathrm{A}$ and $\mathrm{B}$ show positive attitudes towards organ restitution. Thus, from the viewpoint of respecting the autonomy of the donor as well as that of the recipient to the extent possible, it is permissible for $\mathrm{B}$ to give the organ back to A. However, careful and detailed consideration is necessary to determine whether this leaves no room to question the authenticity of B's consent. In our view, there is a relationship that exists between the donor and the recipient, whether it concerns organ restitution or normal organ transplantation. It is not unnatural to add to this relationship an understanding specifically about organ restitution. Whether or not directed donation should be permitted in deceased donor organ transplantation is a controversial topic, and we have a negative opinion regarding this issue. ${ }^{14}$ However, organ transplantation between living persons, in contrast, is essentially based on 'directed' donation. Therefore, the inclusion of the organ restitution understanding in the organ donation process is not unreasonable, and consequently, healthcare professionals, including transplant surgeons involved in living-related organ transplantation, should always weigh heavily the possibility that the donor and the recipient have such an understanding.

Under condition III, where A and B are bound by a kidney donation contract, based on B's ownership rights of the kidney, organ restitution is impermissible if B's intention is not to return the organ, even if A requests it. This would be the reason for A of originally making a loan for use contract that would permit organ return, rather than a donation contract in which A gives his kidney to B. Now, consider again the withdrawal of consent in the context of the organ restitution contract. If withdrawal of consent to the contract is permitted, A might not have originally donated his organ to B. Kidney transplantation enabled B to maintain a high QOL for a certain period of time. If this is attributed to the presence of the organ restitution clause, it is not necessarily bad to include this understanding in the agreement.
While B would have to start dialysis, giving the donated kidney back to A is not necessarily fatal to B.

As stated above, withdrawal of consent to the organ restitution contract is self-contradictory. This is because, if it was possible to later withdraw consent to the organ restitution contract, any merit to A of entering into the contract would be lost, and A would likely not have agreed to the contract in the first place. Therefore, B should not be permitted to withdraw his consent. Certainly, if B was not allowed to withdraw his consent, the donated organ would be returned to A according to the contract, even if B had a negative intention about organ removal. If such is the case, we might find this tragic, and even harbour negative emotions with regard to the fact that B's intention is flatly denied, and organ restitution forced. However, in this case, the original intention of A who donated his organ should be respected more than B's intention, as well as the fulfilment of the agreement. We believe that, in the presence of an authentic organ restitution contract, organ restitution should be obligatory. The B who does not respond to A's request is breaching this obligation. At the same time, we expect B to choose a praiseworthy option. It is nothing but a virtuous act that transcends obligation to conform to the contract, with a sense of gratitude to A's original intention to donate his organ. Rather than calling this an obligation, we encourage B to take such virtuous conduct.

Meanwhile, another issue arises with regard to the ethical evaluation of A who donates his organ on the basis of the contract that includes the organ restitution clause. Certain altruism on the part of A is likely demonstrated in the original organ transplantation between two living persons. If $\mathrm{A}$ is to request the return of the organ which had been transplanted to $\mathrm{B}$, then $\mathrm{A}$ might be deemed selfish, or his altruism may be deemed incomplete or bounded. For these reasons, for A to request the return of the organ might not be considered praiseworthy. However, the wish to have the organ returned is likely granted in the scope of A's rights in the original organ transplantation (from A to B). The good intentions of A, which enabled B to enjoy a high QOL for a certain period of time, must be evaluated maximally.

Next, if A does not wish the organ to be returned (ie, condition II or IV), we think there is no need to put this into reality, honouring A's intention. However, condition II is somewhat unique in that B is the one to offer organ restitution. Since A, who has negative attitudes towards organ restitution, could decline this offer, organ restitution would not be realised under condition II. Nonetheless, it is highly praiseworthy that B offers to give back the donated organ. Condition II is ideal from the perspective of virtue. B, who offers to return the donated organ, is a virtuous person, and possesses the moral virtue of altruism. Furthermore, A is also a virtuous person for refusing B's offer to return the organ. A's virtue could be described as generosity, tolerance or thoughtfulness.

Under condition IV as well, A's intention is likely to be respected, and no need arises for organ restitution. While B may be considered a person with great virtue due to his offer to return the organ, donating the organ despite the wish of A (to not have it returned) would go against A's autonomy.

In conclusion, we accept the possibility that organ restitution could be performed under a contract between concerned parties. The authenticity of the contract itself must be carefully judged. Organ restitution contracts are one-sided contracts, in the sense that they must assume a form that does not permit withdrawal of consent. Given this feature, it is necessary that such contracts be established on the basis of the voluntary, good faith consent of both parties. Consequently, this possibility should be recognised by and the conditions of the contract made rigorous 
under the specific laws of each country. To clarify these conditions once more, they include guarantees of the medical safety of the organ restitution surgery, the voluntary consent of both parties, no coercive intervention by either party or a third party, no exploitation and a reasonable means to determine that these conditions are sufficiently met.

\section{LIMITATIONS AND CLINICAL IMPLICATIONS}

Organ restitution has never been taken up as a serious ethical problem up until now. However, the case presented here does not necessarily lack reality—rather, it casts a new light on realistic issues relevant for future societies and ethics of organ transplantation. This thought experiment might be differently beneficial among the countries and regions since surrounding transplantation situation differs. Thought experiments (like the Trolley Problem, Survival Lottery, the Violinist, Brain in a Vat, the Teletransportation Paradox and the Chinese Room) have long played a very important role in philosophy and ethics. In the pursuit of normative ethics, thought experiments are considered a superb method for teasing out the frameworks underlying our ethical judgments. Of course, it is very important for thought experiments to be relevant. It is true that subsequent kidney failure in living kidney donors is rare. Furthermore, we would expect that the function of the donated kidney in the recipient could be diminished due to a variety of medical reasons. Yet, this is a question of probability, and it is possible that the chance of this sort of situation becoming reality might increase in the future. In other words, a situation could actually occur in which the original donor (A) develops advanced kidney disease, and the donated kidney in the recipient is in a state that allows transplantation medically. Even if the medical potential of performing organ restitution is extremely low, it is nonetheless possible that the original donor (A) might demand that the original recipient (B) sign an organ restitution contract. As long as that possibility cannot be ruled out, we feel that our organ restitution thought experiment is relevant.

For example, in the USA, the median waiting time for a kidney transplant by 2011 was about 4 years. ${ }^{31}$ Previous kidney donors who develop ESRD are highly favoured in the priority listing and are given 4 points, about equivalent to 4 years' waiting time, so they usually will wait only for a short time to receive a next kidney. Moreover, in general, people live three times as many remaining life years with a kidney transplant compared with dialysis. ${ }^{32}$ In this regional context, the physicians should not agree to an operation that would result in putting a kidney transplanted person with preserved kidney function onto dialysis. From the Wainright et al's paper-of the 218 living kidney donors who developed ESRD, 131 were added to the Organ Procurement and Transplantation Network kidney waiting list, of which 97 received deceased donor kidney transplants. ${ }^{3}$ Eleven received living donor transplants. ${ }^{3}$ Sixty-nine listings and 75 transplants occurred before initiation of dialysis. ${ }^{3}$ Accordingly, in countries such as the USA, while organ restitution will not likely be a large public issue, nonetheless the discussion may be important to individual donors and recipients. Conversations contemplating the full implications of kidney donation can strengthen the integrity of the transplantation process.

In contrast to Japan, waiting list of kidney transplantation from brain-dead and non-heart-beating donors is 12100 (as of February 2019) and only 182 transplants were performed in $2018 .^{33}$ Living donor kidney transplants were performed for 1471 cases in $2016 .{ }^{34}$ We can also assume family kidney donors are not so easy to obtain when we see the number of transplants from living kidney donors. Accordingly, it is hard to assume that a living kidney donor who develops ESRD can get a kidney transplant quickly. Moreover, the number of patients receiving dialysis is 329609 (as of December 2016), ${ }^{35}$ and the mortality rates for people on dialysis in Japan are much lower than that in the USA. (Death HR is 1 (Japan) to 3.78 (USA). ) $^{36-38}$ Of course, it may be because the patient population on dialysis in the USA is older and with multiple comorbidities. In either case, the low mortality rates of dialysis, and difficulty in getting the second kidney quickly, organ restitution may become a future real scenario.

In summary, although clinical implications are limited, countries or regions where a living kidney donor who develops ESRD cannot get a kidney transplant quickly, organ restitution may be important to consider, while countries where a living kidney donor who develops ESRD can get a kidney transplant quickly, organ restitution may have different implications.

Lastly, since the primary purpose of this paper is a thought experiment, not to propose organ restitution, we would like to reiterate that unlike transplant from the deceased donors, living organ transplantation often employs 'designated donation' and subsequently impacts relationships. It has a contractlike character. Moreover, though this paper limits the discussion to kidney transplantation, some points are applicable to other types of organ transplantation, such as uterine transplantation between living persons, in the future.

We hope our thought experiment further facilitates the understandings of the nature of living-related organ transplantation, especially kidney transplantation, and will contribute to argument on transplantation ethics.

Acknowledgements The authors thank Dr Stephanie Brown Clark, Director, Division of Medical Humanities and Bioethics, University of Rochester School of Medicine and Dentistry, for her helpful support.

Contributors EN participated in conducting the research in legal and ethical aspects, manuscript writing and revision, and final manuscript approval. KY participated in conducting the research in ethical aspects, manuscript writing and revision, andfinal manuscript approval. ArA participated in conducting the research, collecting references, manuscript revision and final manuscript approval. MHS participated in conducting the research in legal and ethical aspects, manuscript revision and final manuscript approval. RAD participated in conducting the research in ethical aspects, manuscript revision and final manuscript approval. AkA participated in research design, manuscript writing and editing, and final manuscript approval.

Funding The authors have not declared a specific grant for this research from any funding agency in the public, commercial or not-for-profit sectors.

Disclaimer Although AkA is president of the Japan Association for Bioethics (JAB), this letter represents our personal academic analyses and opinions. It does not represent JAB's official position on this issue.

\section{Patient consent for publication Not required.}

Provenance and peer review Not commissioned; externally peer reviewed.

Open access This is an open access article distributed in accordance with the Creative Commons Attribution Non Commercial (CC BY-NC 4.0) license, which permits others to distribute, remix, adapt, build upon this work non-commercially, and license their derivative works on different terms, provided the original work is properly cited, appropriate credit is given, any changes made indicated, and the use is non-commercial. See: http://creativecommons.org/licenses/by-nc/4.0/.

\section{REFERENCES}

1 Toledo-Pereyra LH, Toledo AH. 1954.J Invest Surg 2005;18(6):285-90.

2 Global Observatory on Donation and Transplantation. Organ donation and transplantation activities 2016, 2016. Available: http://www.transplant-observatory. org/download/2016-activity-data-report/ [Accessed 4 Apr 2019].

3 Wainright JL, Robinson AM, Wilk AR, et al. Risk of ESRD in prior living kidney donors. Am J Transplant 2018:18(5):1129-39.

4 Andres A, Morales JM, Lloveras J. Reuse of a transplanted kidney. N Engl J Med 1993;328(22) 
5 Graetz K, Cunningham D, Rigg K, et al. Expansion of the organ donor pool by the reuse of a previously transplanted kidney--is this ethically and scientifically valid? Transplant Proc 2002;34(8):3102-3.

6 Celik A, Saglam F, Cavdar C, et al. Successful reuse of a transplanted kidney: 3-year follow-up. Am J Kidney Dis 2007;50(1):143-5.

7 Kamar N, Rischmann P, Guilbeau-Frugier C, et al. Successful retransplantation of a kidney allograft affected by thrombotic microangiopathy into a second transplant recipient. Am J Kidney Dis 2008;52(3):591-4.

8 Bryan CF, Abdulkarim B, Forster J, et al. A new role for the virtual crossmatch in kidney allograft reuse. Transplantation 2010;89(6):764-5.

9 Kadambi PV, Chon WJ, Josephson MA, et al. Reuse of a previously transplanted kidney: does success come with a price? Clin Kidney J 2012;5(5):434-7.

10 Park SJ, Oh SH, Kang MS, et al. Reuse of a previously transplanted kidney from a deceased donor using Luminex virtual crossmatching: a case report. Transplant Proc 2014:46(6):2083-5.

11 Yıldız S, Çelik A, Camsari T. Long-Term follow-up of a reused kidney allograft. Am J Kidney Dis 2016;67(6)

12 Locke JLaslett P, ed. Two treatises of government. 287. Cambridge: Cambridge University Press, 1988.

13 Anarchy NR. State and utopia. 171. New York: Basic Books, 1974.

14 Nakazawa E, Maeda S, Yamamoto K, et al. Reuse of cardiac organs in transplantation: an ethical analysis. BMC Med Ethics 2018;19(1):77.

15 Attas D, Department of Philosophy, Florida State University. Freedom and SelfOwnership. Soc Theory Pract 2000;26(1):1-23.

16 Cherry M. Kidney for sale by owner: human organs, transplantation, and the market. Washington, DC: Georgetown University Press, 2005.

17 Lippert-Rasmussen K. Against Self-Ownership: there are no Fact-Insensitive ownership rights over one's body. Philos Public Aff 2008;36(1):86-118

18 Demme RA. Ethical concerns about an organ market. J Natl Med Assoc 2010;102(1):46-51.

19 Cohen GA. Self-ownership, freedom, and equality. Cambridge: Cambridge University Press, 1995.

20 Arneson RJ. SELF-OWNERSHIP and world ownership: against LEFT-LIBERTARIANISM. Social Philosophy and Policy 2010;27(1):168-94.

21 Civil Code (Japan). Revised. article 521-522, 2017. Available: http://www.moj.go.jp/ content/001264450.pdf [Accessed 2 Sep 2019].

22 Organ Transplantation Act (Japan). Revised. article 11, 2009. Available: http://www jotnw.or.jp/jotnw/law_manual/pdf/organtransplant-law.pdf [Accessed 2 Sep 2019].

23 Richards R. Celebrities and spiritual gurus: comparing two biographical accounts of kidney transplantation and recovery. AJOD 2015;4(1).
24 Thomson JJ. A defense of abortion. Philosophy and Public Affairs 1971;1(1):47-66.

25 Schumaker M. Sharing without reckoning. Waterloo, Ontario, Canada: Wilfrid Laurier University Press, 1992

26 Rachels J. The elements of moral philosophy. 2nd edn. New York: MacGraw-Hill, Inc, 1993: 163.

27 McNamara P. Supererogation, inside and out: Toward an adequate scheme for common sense morality. In: Timmons M, ed. Oxford studies in normative ethics, volume I. Oxford University Press, 2011: 202-35.

28 Schumaker M. Sharing without reckoning. Waterloo, Ontario, Canada: Wilfrid Laurier University Press, 1992: 67-70.

29 Urmson JO. Saints and Heroes. In: Melden Al, ed. Essays in moral philosophy. Seattle: University of Washington Press, 1958.

30 Portmore DW. Supererogation. In: Crimmins JE, Long DC, eds. Encyclopedia of utilitarianism. New York: Bloomsbury, 2013: 538.

31 United States Renal Data System. Chapter 6: transplantation. in: 2018 USRDS annual data report, volume 2: ESRD in the United States. 2018:427-462. Available: https:// www.usrds.org/2018/download/v2_c06_Transplant_18_usrds.pdf [Accessed 4 Apr 2019].

32 United States Renal Data System. Chapter 5: mortality. in: 2018 USRDS annual data report, volume 2: ESRD in the United States. 2018:411-426. Available: https:// www.usrds.org/2018/download/v2_c05_Mortality_18_usrds.pdf [Accessed 4 Apr 2019].

33 Japan Organ Transplant Network Homepage. Ishoku ni kansuru data [Data on transplantation]. Available: http://www.jotnw.or.jp/datafile/index.html [Accessed 4 Apr 2019]

34 The Japan Society for Transplantation. Data de miru zoukiishoku [Looking organ transplantation through data]. Available: http://www.asas.or.jp/jst/general/number/ [Accessed 4 Apr 2019].

35 Masakane I, Taniguchi M, Nakai S, et al. Annual dialysis data report 2016, JSDT renal data registry. Renal Replacement Therapy 2018;4(1).

36 Goodkin DA, Bragg-Gresham JL, Koenig KG, et al. Association of comorbid conditions and mortality in hemodialysis patients in Europe, Japan, and the United States: the dialysis outcomes and practice patterns study (DOPPS). J Am Soc Nephrol 2003;14(12):3270-7.

37 Robinson BM, Bieber B, Pisoni RL, et al. Dialysis outcomes and practice patterns study (DOPPS): its strengths, limitations, and role in informing practices and policies. Clin J Am Soc Nephrol 2012;7(11):1897-905.

38 Stegmayr BG. Sources of mortality on dialysis with an emphasis on microemboli. Semin Dial 2016:29(6):442-6. 